\title{
Educational interpreting: A dynamic role model
}

\author{
Herculene Kotzé \\ School of Languages, Potchefstroom Campus, North-West University, South Africa \\ E-mail: herculene.kotze@nwu.ac.za
}

\begin{abstract}
This article aims to describe the challenges faced by educational interpreters within a professional context with regard to role fulfilment and existing role models. This will be carried out by exploring the notions of 'roles' and 'norms' within Translation Studies (which includes interpreting) and investigating how these relate to and influence educational interpreting. The article will offer findings emanating from an extensive study and, by adopting a normative approach, provide an adapted role model specifically designed for educational interpreting.
\end{abstract}

Keywords: translation, interpreting, educational interpreting, role, role fulfilment, role model

\section{Introduction}

According to Baker (2005:4), research carried out in previous years on the role of the translator may have contributed to an uncritical and unrealistic image of this role, and needs to be revisited. She argues that the role of the translator must not be viewed as being outside of or between cultures, but should rather be viewed as an integral part of any communicative interaction which involves primary and secondary participants. In this regard, Gile (2003:48) states that the focus should be on people and not on texts as "[t]ranslators are expected to serve not texts, but people, with particular intentions and interests". Due to the fact that interpreting forms part of the definition of "translation", the latter being an encompassing term for languagerelated activities, one can argue that Gile's assertion is also true for interpreting. For this reason, resources from translation studies and interpreting studies will be used intertextually.

When taking a closer look at the literature on the subject, however, it becomes clear that the "channel" description still enjoys great normative support and, in many instances, is still perceived as the "correct" role to be accepted by interpreters. This view entails that an interpreter is a mere conduit or channel who does not take part in communicative actions (Tate and Turner 2002:374). This is supported by the well-known mechanistic Code Model which states that the interpreter should be invisible and uninvolved in the communicative act. Despite many researchers arguing for the untenability of this model (amongst others, Angelelli 2000a, 2000b, 2003; Tate and Turner 2002:374; Wadensjö 1998:7), Wadensjö (1998:7) admits that the practical way in which the role fulfilment of interpreters still plays out, is greatly influenced by this model. 
Conversely, an evolving movement in the direction of a more "involved" role model is also noticeable. Since 1976, Anderson $(1978,2002)$ has argued that the role of the interpreter (regardless of type or mode) is marked by uncertainty and contradictions. Furthermore, he asserts that this role is complex and is dependent on various expectations from all relevant parties involved in the interpretation process. Linell (1997:53) and Wadensjö (1998:41) further explore this idea and observe that the interactive nature of the communicative event requires a much more involved role from the interpreter - an element neglected in the literature on this topic up until now. The uncertainty with regard to role fulfilment of interpreters is clearly articulated by Hale's (2004) remark on an apparent gap in specific role expectations of interpreters, and concludes that the profession is undergoing an "identity crisis".

To add more to this apparent identity crisis, Fozooni (2006:283) maintains that a new view on the role of the translator developed over time which focused more on cultural aspects. Furthermore, it appears as if Van den Broeck and Lefevere's (1979:10) preference for viewing a translator (and therefore also an interpreter) as a facilitator who simultaneously needs to cope with receiving a source text and sending a target text, gained substantial ground (see Kotze and Verhoef 2001, Verhoef, Carstens and Van de Poel 2003, Bedeker and Feinauer 2006, Bothma and Verhoef 2008). With this in mind, it becomes clear that the role which interpreters fulfil is by no means easily definable. In addition, a multitude of views on possible roles also exists.

Angelelli (2000a, 2000b, 2003, 2004a:71-84, 2006) and Mullamaa (2006:49-50, 2009:50-58) make it clear that the role interpreters fulfil should be investigated. They also hint that such investigations should include interpreters' self perceptions of their roles against the background that interpreting should be viewed as a socially-bound activity. According to Pöchhacker (2001:411), the different levels of interaction between communication participants within an interpreted event largely guide the role fulfilled by an interpreter, and the role truly depends on the definition of the social interaction context. The following quote by Pöchhacker (cited in Snell-Hornby (2006:134)) also proves that the role of the interpreter is still largely undefined:

Simultaneous interpreters have undergone a process of anonymizing and mechanizing that during the course of five decades has, as it were, turned them from admired acrobats into necessary technocrats of international communication.

In short, if interpreting is seen as a discernable language practice activity, and the role of the interpreter in mediating communication is studied, it will be clear that this role has not yet been clearly defined.

With this in mind, this article defines educational interpreting within the socially-bound environment in which it is typically found. Furthermore, it is argued that, as a discernable language practice activity, the role of the educational interpreter should be determined by its social environment. A normative investigation will be carried out in terms of this social environment in order to determine to what extent it has an influence on the educational interpreter. The article will conclude by offering an adapted role model specifically designed for educational interpreting. First off, however, the term "educational interpreting" will be defined to serve as a starting point. 


\section{Defining educational interpreting}

The possibility that the educational interpreter's role within the South African context entails more than simply acting as a channel was researched by Olivier (2008) during a pilot project relating to educational interpreting. Olivier determined that demonstrable differences exist between the conference interpreter's and the educational interpreter's respective approaches to their interpreting tasks, which paved the way for the current study. In addition, Bothma and Verhoef (2008), Partridge (2008) and Verhoef and Blaauw (2009) conducted separate studies which all focused on educational interpreting as a type of community interpreting. In addition, studies by Shackman (1984, in Merlini and Favaron 2003:208), Pöchhacker (2007), Swabey (2007) and Rudvin (2006) offer sufficient results to accept educational interpreting as a type of interpreting which is determined and governed by the social interaction within which it takes place, thereby solidifying educational interpreting as a type of community interpreting.

This finding gives rise to the possibility that educational interpreting, and therefore the role of the educational interpreter, should be approached differently from other types of interpreting because it has demonstrable differences and requirements. This possibility is supported by Niska's (2002:134) theory, which states that what is expected from interpreters varies according to context, domain and situation, although expectations are usually generic.

When community interpreting in particular is researched, Niska (2002:137-138) states that the role fulfilled by community interpreters can only be fully understood if it is accepted that a spectrum of role options is available. These roles may vary between a neutral function, where the interpreter acts solely as a linguistic channel, and an active advocate, where the interpreter acts purposefully on behalf of one or more of the participants in the interpreting situation. He contends that the interpreter's role should be classified according to socio-cultural, linguistic and cognitive skills, but that neglecting the macro context in which the interpreting activity takes place may negatively influence the interpreting process and product. The implication here is that the different variables within the educational environment (for instance, a lecturer's or teacher's teaching style) may have an influence on the interpreting process and product and may in turn influence all of the roleplayers' perceptions of the communicative opportunity. In order to determine which variables are relevant, it is necessary to explore the existing norms in educational interpreting.

\section{A normative approach to the educational interpreter's role fulfilment}

On a basic level, Toury (1999:13) defines norms as regularities within translation behaviour and, in doing so, gives expression to the complex process which is followed to complete a set of mutually agreed-upon values within a certain social group (also consult Reeves 1994:42, Tate and Turner 2002:374, Marzocchi 2005:89). However, the simplicity of his definition is misleading as Toury $(1999: 15,2000: 200)$ states that what is normative cannot be found in regularities alone. On the other hand, the fact that regularities in translation behaviour are a reality proves that a negotiated and accepted system of norms does exist.

The existence of norms in translation behaviour implies that it is difficult to keep a fundamentalist and prescriptive hold on it, due to the fact that norms are found within unstable social environments. The terms "correct" and "fitting" may be assumed to be key descriptions within a community of practice to describe sanctioned and agreed-upon conventions. However, 
"norms" are probably more complex than that. Toury (1999:15) argues that norms come into being in translation (and, by definition, also interpreting) during a decision-making process which allows for the consideration of alternatives and the recognition of different variables (also consult Linell 1997:64, Shlesinger 1999:69).

In simple terms, Davis (1994:97) states that people utilise their social skills to negotiate similarities regarding behaviour and actions. He argues that reality may seem stable and regulated only because we take collective decisions about what is suitable and acceptable within certain circumstances. These similarities are always negotiated, these negotiations take time, and the result can be seen in conventions which certain members of a group will follow within specific circumstances. He continues by saying that these similarities do not stay constant. If the group continues to exist, these similarities will constantly be subject to re-negotiation, a process which is very much alive.

In this regard, Toury (1999:25) argues that norms are accepted as the general values or ideas that members of a group have in common. These norms act instructionally within certain situations according to what is right or wrong and what is acceptable or not. Norms can therefore be used to investigate actions and/or behaviour within a given social situation. They can also act as a gauge according to which actions and/or behaviours can be evaluated. For the purposes of this article, this assumption is accepted and utilised to critically view the role of the educational interpreter and, in doing so, attempts to determine if there are existing accepted norms within the practice of educational interpreting. This socio-cultural construct is useful due to the fact that any communication which requires language practice activities takes place within a social situation. Applying this construct to language practice activities therefore allows for an in-depth look into the role of the educational interpreter.

Toury (2000:198) proposes that three types of norms encompass all practical aspects of language practice on a normative level; these include (i) initial norms, (ii) preliminary norms and (iii) operational norms. Initial norms involve the basic strategic decision that the translator/interpreter takes regarding his/her approach towards the task at hand, i.e. whether or not his/her loyalty lies with the author or with the target culture and how this then influences the completion of the task. Preliminary norms contain the typological parameters which influence the task, for instance text type or type of interpreting and their origins. Finally, operational norms describe the decisions which are taken in reality and differentiate between matricial and textual/linguistic/form norms. When these three norms are used to determine whether a set of norms exists within educational interpreting, the focus is on the interaction between the different types of norms. Specifically, what is investigated is the difference between that which is expected of the educational interpreter and that which takes place in reality.

A practical example of this interaction can be found in Shlesinger's (1999:65-77) study of the choices regarding cognitive limitations or norms made by court interpreters within given situations. In her study, interpreters used simplification during their production, which may indicate tension between two sets of norms, namely expectancy norms versus performance norms. Expectancy norms can be described as the court's implicit or explicit expectations of the interpreter; performance norms can be described as the interpreter's perception of the role he/she fulfils, including what must be done in order to fulfil his/her role successfully. 
The current study connects Toury's preliminary and operational norms with Shlesinger's expectancy and performance norms. In both the researchers' cases, preliminary or expectancy norms refer to what is expected of the interpreter, i.e. what the interpreter is supposed to do within a certain situation or environment. Different situations and environments may influence what is perceived to be "correct" or "acceptable" within a specific situation, but they do not always take the reality of the situation into account. In contrast to this, operational and performance norms focus on what really happens in a given situation. In addition, Shlesinger warns against theorists making statements about what "must" and "must not" be done as there are fundamental differences between explicit claims and behaviour as manifested in reality. A good example of this can be found in court interpreting, where interpreters tend to condense information (Shlesinger 1999:70). In addition, Schjoldager (1994:84) refers to the norm in simultaneous interpreting where interpreters may add to the source text if the added information is relevant. She states that users of simultaneous interpreting prefer these types of additions to incomplete sentences, and argues that this norm is probably unique to simultaneous interpreting. This uniqueness, however, is not limited to one type of interpreting, and evidence of these types of norms is confirmed by Gile (1994:153-158), Shlesinger (1999) and Poyatos (1997).

What is clear is that expectations do not necessarily coincide with reality. Toury (1999:28) confirms this by saying that different norms in especially comprehensive and heterogeneous groups are not uncommon. The solution, therefore, probably lies in how the interpreter manoeuvres his/her way around these norms, and also where a distinct role definition is embedded. The interpreter, in his/her search for what he is "supposed" to do, most likely fulfils more than one role precisely because he is "searching".

As has been stated, it can be assumed that interpreting (and, by extension, educational interpreting) always takes place within a social setting. Educational interpreting, by definition, also always takes place amongst a multitude of socio-cultural constructs. This implies that these socio-cultural aspects may also influence the role fulfilment of the interpreter. To determine exactly how these aspects may exert this influence, it is important to look briefly at the prevalence of culture in education with regard to the shaping of norms within language practice activities.

\subsection{Culture and norms}

According to Fozooni (2006), the language practitioner - as "cultural hermaphrodite" (Fozooni 2006:283) - crosses the cultural divide via meaning transfer and insists on creating meaning with the original author and audience. In saying this, Fozooni (2006:294) attempts to prove that 'invisibility' and 'impartiality' are concepts which are simply illusions. He offers the cultural hermaphrodite the opportunity to come up with creative and innovative solutions to challenges within the translation environment. In doing so, a language practitioner would then be allowing him-/herself to become a cultural creator of knowledge. In this regard, Bhabha (1994:64) adds that it is indeed necessary to go further than simply looking at the usual and initial subjective narratives and to focus on those moments which are produced during the articulation of cultural differences. He calls these moments "in-between spaces" and argues that these spaces allow for the search for a new identity and innovative approaches regarding the role of the interpreter. 
Pym (1997:177) uses the term "intercultures" to illustrate how translators work and live. This includes opinions and practices which are found within overlapping areas between cultures, when people from more than one culture meet. However, he adds that interculturality should not be confused with the fact that people from different cultures are found within one community or political unit. This points to the idea that the presence of different cultures allows for individuals to, in a manner of speaking, cultivate their own culture. This confirms Fozooni's argument that the role of the language practitioner has evolved to such an extent that a new form of linguistic expression is found when the focus is diverted from single cultures and their representations, to cultures becoming commonplace. In this regard, Mullamaa (2006:32) readily accepts Pym's proposal by stating that if it is possible that the identities of people who live among different cultures can influence one another, it is probable that people who act as mediators within these cultures (in this case interpreters) will also be influenced by these cultures. She adds that this interculture vision describes what professional language practitioners already experience, namely a continued balance between what is familiar and what is unfamiliar. Fozooni's (2006:283) statement completes the picture when he says that the interpreter should in actual fact not function between two cultures and languages, but should be seen as playing an integral part in creating the message in the target language. Figure 1 represents Pym's idea of intercultures:

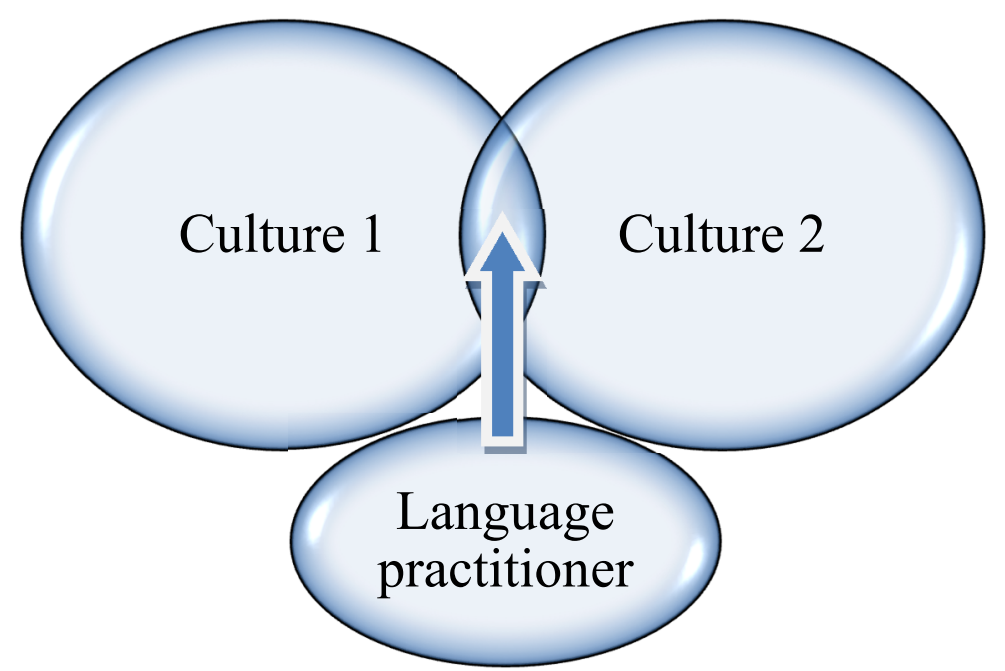

Figure 1. Intercultures (Pym 1997:177)

Based on Pym's (1997:177-178) proposal that the language practitioner will inevitably be influenced by the cultures in which s/he works, it is argued here that the educational interpreter will also be influenced by the cultural environment in which s/he works. Factors at play here may include the social history of the educational environment, the cultures within which the interpreter works as well as practical factors s/he encounters on a daily basis, to name a few. According to Toury (1999:28), one of the consequences of this working environment is that it has become a prerequisite for translators to accept the norms within a specific situation in order to determine the acceptability or correctness of a given action or set of behaviours within that situation. This in turn allows the translator to properly manoeuvre between all the variables which may influence behaviour. Toury adds that this reality creates an environment which is very challenging to an interpreter as not only must the interpreter handle linguistic aspects (e.g. source-text complexity, systemic differences between languages, personal cognitive 
constraints) but also socio-cultural factors which are ever-present in each interpreting opportunity. In addition, Bhabha (1994:77) refers to the value of in-between spaces because it is here where communal interests of cultural value are negotiated.

What becomes evident from this discussion regarding norms and the influence of different cultures is that any social activity essentially involves active, dynamic norms which are negotiated among members of a specific community. When the focus moves to norms and the role of the educational interpreter, it can be accepted that these negotiated and accepted norms may alter the role of the interpreter and adapt it until it is acceptable and applicable within a given community. The presence of norms also offers a mechanism with which these norms can be identified and evaluated. It is also a clear reality that different cultures within a community are intertwined with norms and their creation, and that these norms and their processes of creation will inevitably influence the role of the interpreter.

At this point, an in-depth look at the role of the educational interpreter is necessary, including the social construct which is inherent to norms in interpreting situations. This will enable us to determine whether norms are really present within educational interpreting, as proposed above.

\subsection{A normative role description for educational interpreting and interpreters}

Gentile, Uldis and Vasilakakos (1996:31) describe role fulfilment as follows:

Role is a social science construct used to explain behaviour and examine attitudes between at least two participants in any social situation. [...] The role of the interpreter, like other roles, derives from observed behaviour over time and from evaluation of behaviour vis-à-vis that expected by professional associations or other occupational or social groupings.

Thus far we have ascertained that the interpreter fulfils his/her role within a social event, and that this behaviour, which is deemed acceptable within that situation, may eventually be expected of him/her and in turn become the norm. Based on Toury's research $(1995,1999$, 2000) and normative theories by Goffman (1961) and Gercek (2008) normative behaviour within educational interpreting will now be investigated.

Goffman's (1961) research on the classification of roles is based on the assumption that situational social interaction encompasses any interaction, given that members of a group communicate with each other on a regular basis (Goffman 1959:26). At this point, it can be accepted that the established ideas people have about an activity and the role that they should fulfil when taking part in this activity is related to normative behaviour. Within the interpreting environment, this relates to how interpreters, users and lecturers believe interpreters should act during an interpreting activity. It thus includes the perceptions of the interpreter's role and disregards real experiences (Gercek 2008:11). All participants within the interpreting activity therefore have a preconceived idea of how they and the other participants will act, and evaluate and interpret the manifestation of role fulfilment accordingly.

The social environment associated with interpreting raises the issue of interpreters' perceptions of the role they fulfil. This relates to Toury's (1995:53) and Pym's (2010) concept of 'translatorship' which involves the translator being capable of fulfilling a social role as assigned 
by a specific community. This concept and ability means that the interpreter will approach his/her role fulfilment in a specific manner, tailor-made to the needs of the community, which means that the interpreter will obviously have a specific perception of the role s/he fulfils. Added to this, Angelelli (2003:16) offers great insight as she determined that very little research has yet been carried out on the perceptions that interpreters in particular have of their role and issues concerning it. This relates to Anderson's (2002:209) statement that perceptions may indeed influence role fulfilment, as well as Angelelli's (2004a:71) statement that different interpreting types may have different role approaches. Therefore, in order to determine what the norms are within educational interpreting, it is important to study the perceptions of role fulfilment within educational interpreting, as these perceptions may have an influence on existing norms and their establishment.

In this regard, Toury (2000) and Shlesinger (1999) offer theoretical parameters which can be utilised to evaluate existing norms and to determine whether there is a difference between the preliminary or expectancy norms and operational or performance norms within educational interpreting. Once this has been done, the role distance (Goffman 1961) of educational interpreting can be identified; this is "when a conflicting discrepancy occurs between, on the one hand, the self generated in actual social interaction, and, on the other, the self associated with a formal status and identity" (Wadensjö 1998:85). In other words, Gercek (2008:12) describes role distance as the difference between that which is expected and that which takes place. These findings would then practically illustrate what takes place in situations of educational interpreting.

The theories discussed above are presented in Figure 2. This graphic representation illustrates the ongoing dynamic relationship between normative behavioural expectations within the interpreting environment. Theoretically speaking, these behavioural expectations are supposed to be embodied in predictable role behaviour. However, due to continually changing practical interpreting conditions, this dynamic relationship can be observed in different types of role distance.
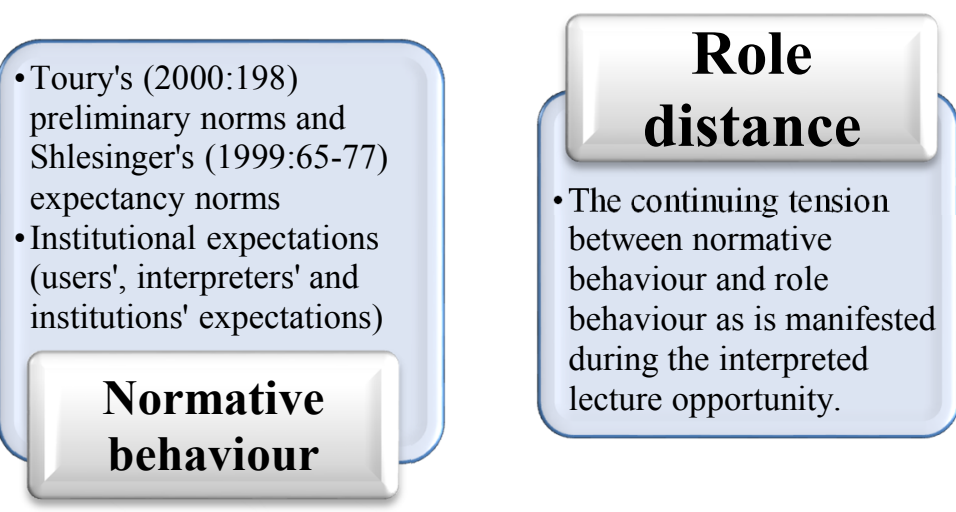

- Toury's (2000:198) operational norms and Shlesinger's (1999:65-77) performance norms - Interpreting behaviour in reality

Role behaviour

Figure 2. A normative role description of educational interpreting 
In order to test this role model, Niska's (2002:137-138) role pyramid was used as the theoretical basis for the data collection of this study. Niska's role pyramid asserts that the community interpreter spends most of his/her interpreting time fulfilling the role of conduit, but that it may sometimes be necessary to move within a spectrum of role possibilities, depending on the situation.

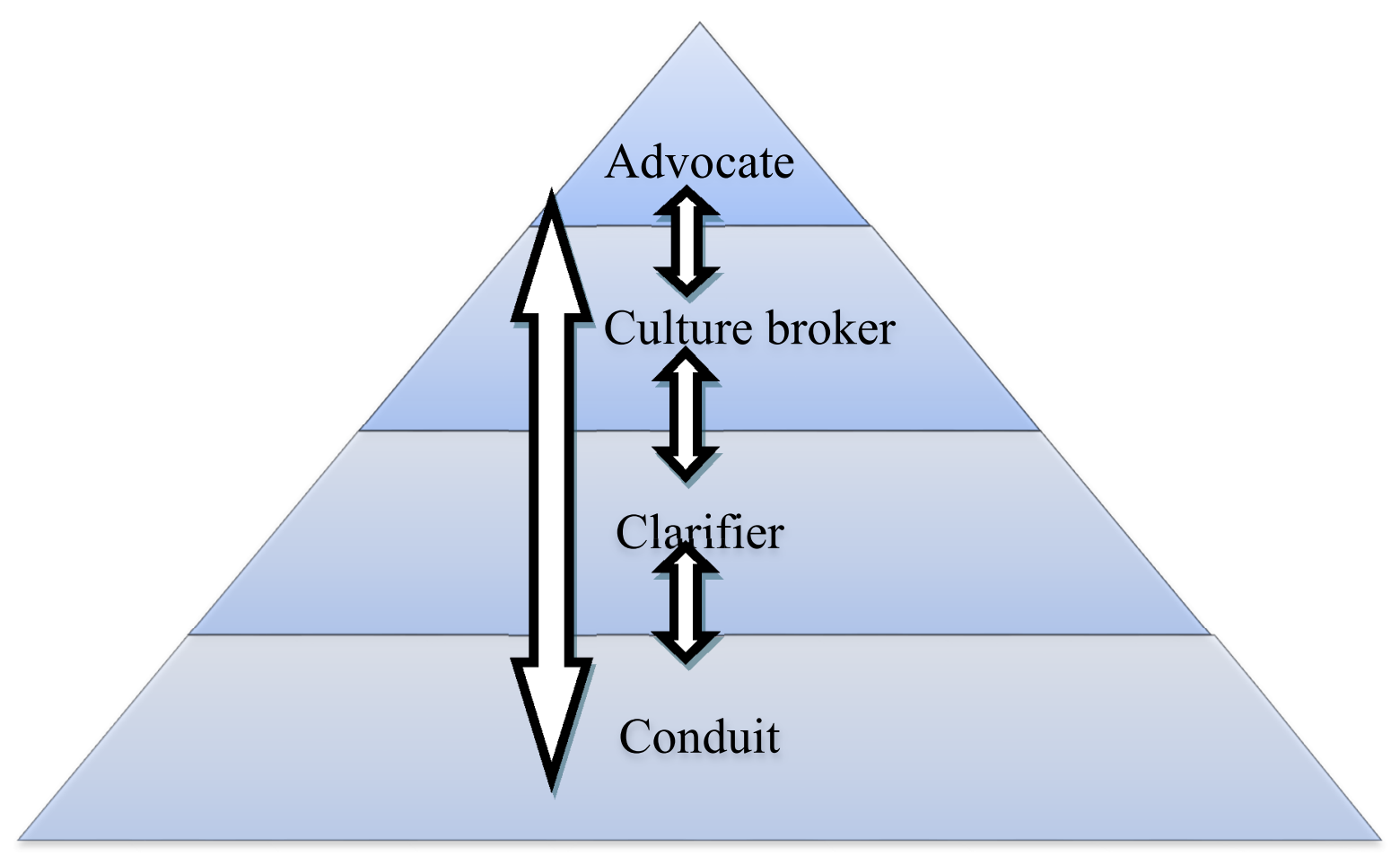

Figure 3. Niska's (2002) role pyramid for community interpreting (arrows added by author)

When acting as a conduit, the interpreter only offers the information in the source text. However, it may sometimes be necessary to offer a little more information to ensure the message is accessible. In this case, the interpreter then assumes the role of clarifier (i.e. moving upwards in the model in Figure 3). The culture-broker role is even more involved and entails that the interpreter actively ensures that cultural borders are crossed successfully and that misunderstandings are prevented. At the uppermost level, the interpreter advocates for the user. This is the most involved role and, as is indicated by the pyramid shape of the model, is also the role in which the interpreter spends very little time. As advocate, the interpreter acts on behalf of the user, for instance, in cases where the user has been offended.

The underlying principle of Niska's (2002) model is that interpreters fulfil more than one role and, more importantly, do so simultaneously. This is indicated in Figure 3 by both the smaller and the larger arrows which point towards the interpreter's versatility. The value of this model lies in the fact that educational interpreters are no longer bound to only one role, and may choose which role is more fitting in a specific environment and situation.

Based on the theoretical models by Toury (1995), Shlesinger (1999) and Niska (2002), data were collected from the following consenting institutions: Frikkie Meyer High School, 
Transoranje School for the Deaf, the Potchefstroom Agricultural College and the Vaal Triangle and Potchefstroom campuses of the North-West University. The other institutions which were approached chose not to take part in the study.

In the following section, the methodology will be discussed and the collected data will be analysed and discussed in conjunction with the theories already presented.

\section{Methodology and data collection}

\subsection{Introduction}

This study is situated within the parameters of Grounded Theory as originally developed by Glaser and Strauss (1967) and expanded upon by Strauss and Corbin (1990, 1994, 1997, 1998). This research model is data-driven and focuses on systematic, inductive theory development based on an extensive data corpus. Typical of the distinctive iterative processes of Grounded Theory, a step-by-step approach was employed and each step followed on and was dependent on the previous (consult Borgatti n.d.). For the sake of triangulation, a typical mixed-methodcollection approach was followed, where the scope of the research problem was researched qualitatively in available literature and data sources, from which certain trends and patterns regarding typical role expectations of educational interpreters were identified. Next, these broad trends and patterns were tested quantitatively by means of a questionnaire which was distributed to a representative sample of respondents. These findings were, once again, subjected to qualitative confirmation by a second round of data collection comprising interviews and/or focus-group discussions in smaller representative samples within the educational interpreting environment. These steps precisely determined the trends within educational interpreting regarding the role expectations of the educational interpreter.

\subsection{Phase 1: Literature review}

The first phase of data collection involved an extensive literature and data investigation, including studies on educational interpreting. This was carried out in order to form a synthesis of existing points of departure and develop a coherent model. This phase thus consisted of a normative investigation regarding the role of the educational interpreter, which resulted in a theoretical model for the role fulfilment of educational interpreting. These findings have already been discussed in section 3 .

\subsection{Phase 2: Quantitative investigation}

The second phase consisted of a quantitative investigation during which the trends identified during the first phase of data collection were generalised and tested. This phase involved the distribution of a closed-ended questionnaire to different stakeholders involved in educational interpreting; these stakeholders were recruited by utilising the availability sampling method. Due to the limited research population, institutions involved in educational interpreting in South Africa were included in the research population under investigation in the current study. As previously mentioned, all of the following institutions were approached regarding the distribution of questionnaires, however only the first four in this list opted to take part in the study: Transoranje School for the Deaf, Frikkie Meyer High School, the Potchefstroom Agricultural College, the Vaal Triangle and Potchefstroom campuses of North-West 
University, the University of the Free State, Durban University of Technology and the University of Johannesburg. It was agreed that the data collected from these institutions were comparable as they all practised the same type of interpreting.

The standard procedure regarding the development, validation, distribution and processing of the questionnaire was followed with support from consultants employed by North-West University's Statistical Consultation Service. In Table 1, an exposition is given of the respondents of the questionnaire.

Table 1. Respondents of quantitative questionnaire

\begin{tabular}{|l|c|c|c|c|c|c|}
\hline Respondents & NWU (Potch) & NWU (VT) & PAC & HSFM & TOSD & Total \\
\hline Interpreters & 14 & 2 & 2 & 3 & 2 & $\mathbf{2 3}$ \\
\hline Users & 63 & 90 & 43 & 21 & 14 & $\mathbf{2 3 1}$ \\
\hline Teaching staff & 5 & 5 & 4 & 1 & 5 & $\mathbf{2 0}$ \\
\hline
\end{tabular}

\subsection{Phase 3: Qualitative investigation}

Phase 3 followed on the previous two phases and was based on the insights gathered from them. Methods typical of qualitative research were employed as collection techniques; in addition to observations, structured interviews and/or focus-group discussions were held. Although observation was employed in each case, a choice was made between structured interviews and focus-group discussions based on practical considerations, and iterations were followed until data saturation was reached. The data collected from this phase will not be discussed in this paper.

\subsection{Phase 4: Data analysis and discussion}

The last empirical phase was the interpretation phase, also typical of Grounded Theory, where data categories unfold and can be identified (also known as "open coding"). These categories can then be measured or tested in terms of the theoretical model (known as "axial coding") and the eventual indication of existing connections between the theoretical model and the data (known as "selective coding" (Cresswell 2009:191)) takes place.

\subsection{Research findings}

The quantitative role-related findings were as follows: Question 1 in Section 2 of the first questionnaire asked the respondents which role, based on Niska's (2002) role pyramid, they expected the interpreter to fulfil. The answers are represented in Figure 4. 


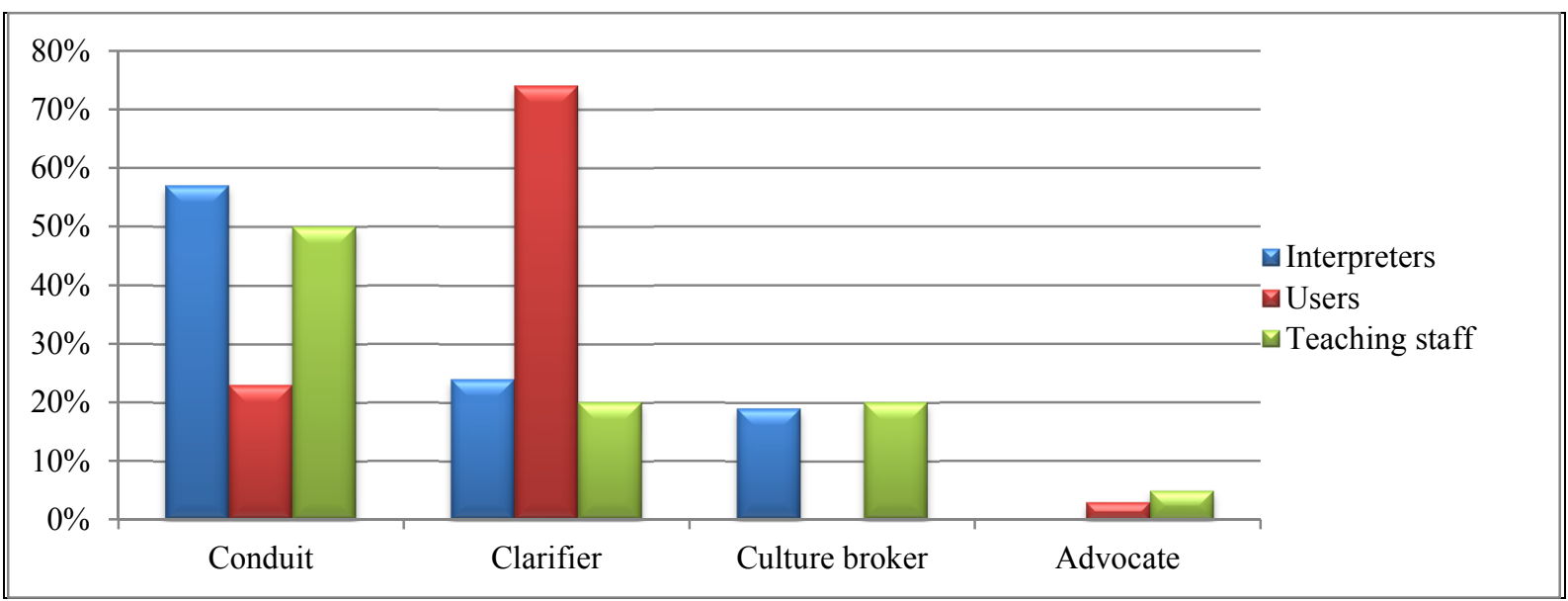

Figure 4. Respondents' expected role choices based on Niska's (2002) role pyramid

The responses from this question indicate that the respondents prefer the clarifier role. What is also evident is that the interpreters and teaching staff both prefer the conduit role, which may indicate that the Code Model is still preferred in reality. However, if Niska's model is interpreted correctly, it may simply indicate that his model is applicable here and that any community interpreter spends most of his/her time fulfilling the conduit role. On the other hand, the fact that the users prefer the clarifier role emphasises the possibility that expectations and reality do not coincide, and that the various roleplayers' perceptions differ from each other.

Question 2 in Section 2 of the first questionnaire asked the respondents which role, based on Niska's (2002) role pyramid, the interpreter in their lectures fulfils in reality. The answers are represented in Figure 5.

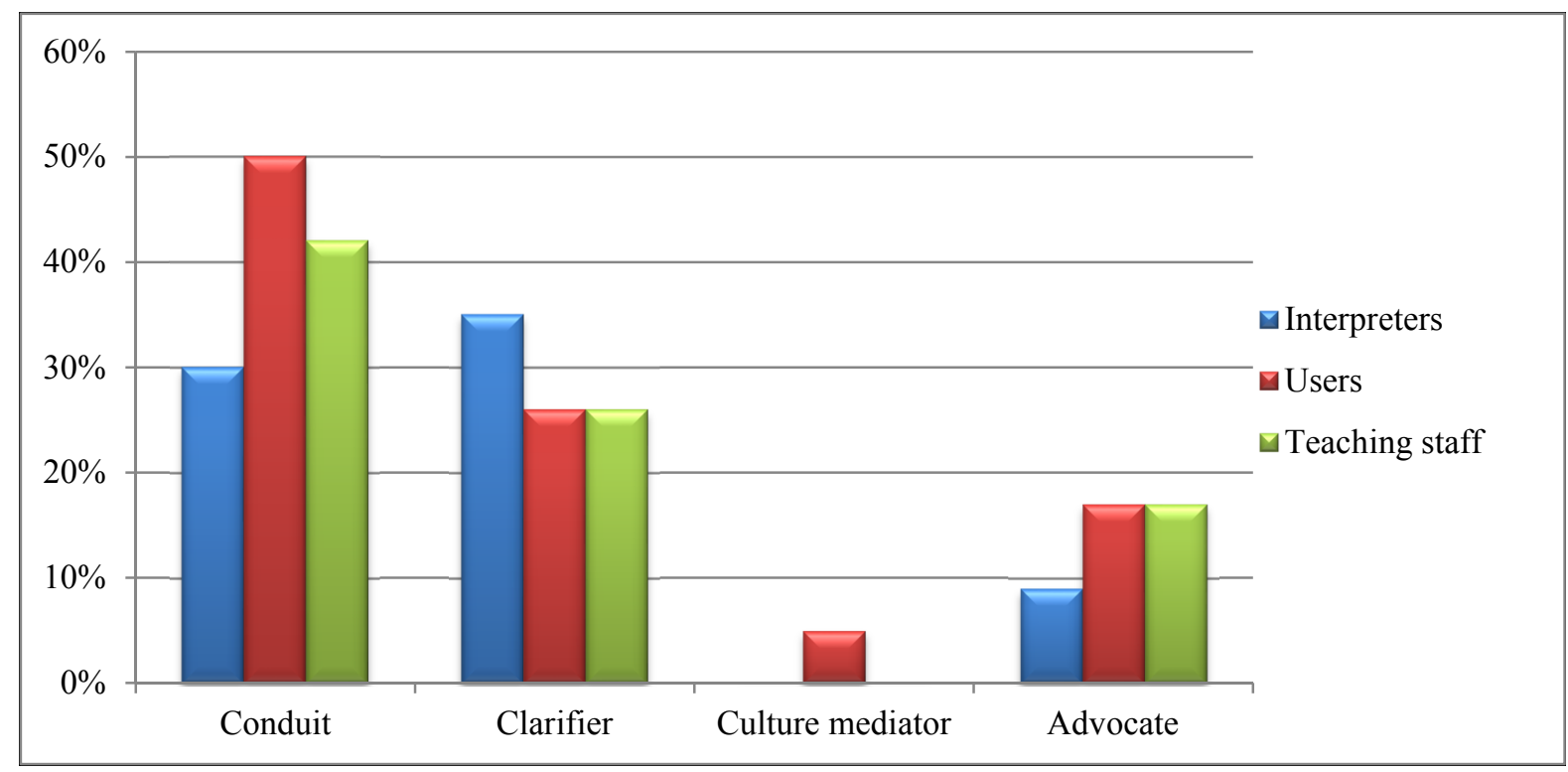

Figure 5. Respondents' role choices (Niska 2002) based on reality

What is significant here is the fact that the users, who indicated the clarifier role to describe the expected role of the interpreter, selected the conduit role to describe which role the interpreter 
fulfils in reality. This confirms and solidifies the difference between normative expectations and reality. The same trend can be seen amongst the interpreters: initially they chose the conduit role to describe the interpreter's expected role, but when asked to select which role the interpreter fulfils in reality, they chose the clarifier role. However, the findings of the teaching staff still adhere to normative expectations of reality.

In addition to the data presented and discussed above, some of the respondents preferred to select more than one role description to answer the questions:

- $\quad 13 \%$ of interpreters selected a combination of the clarifier and culture-broker roles, $9 \%$ selected a combination of the clarifier and advocate roles and $4 \%$ chose a combination of the conduit and advocate roles.

- $\quad 2 \%$ of users preferred to combine all four role descriptions to act as one complete role description.

- $\quad 5 \%$ of teaching staff chose to combine the conduit and culture-broker roles, $5 \%$ preferred to combine the conduit, clarifier and culture-broker roles and $5 \%$ selected a combination of the conduit and advocate roles.

All of the quantitative data were combined and is represented in Figure 6:

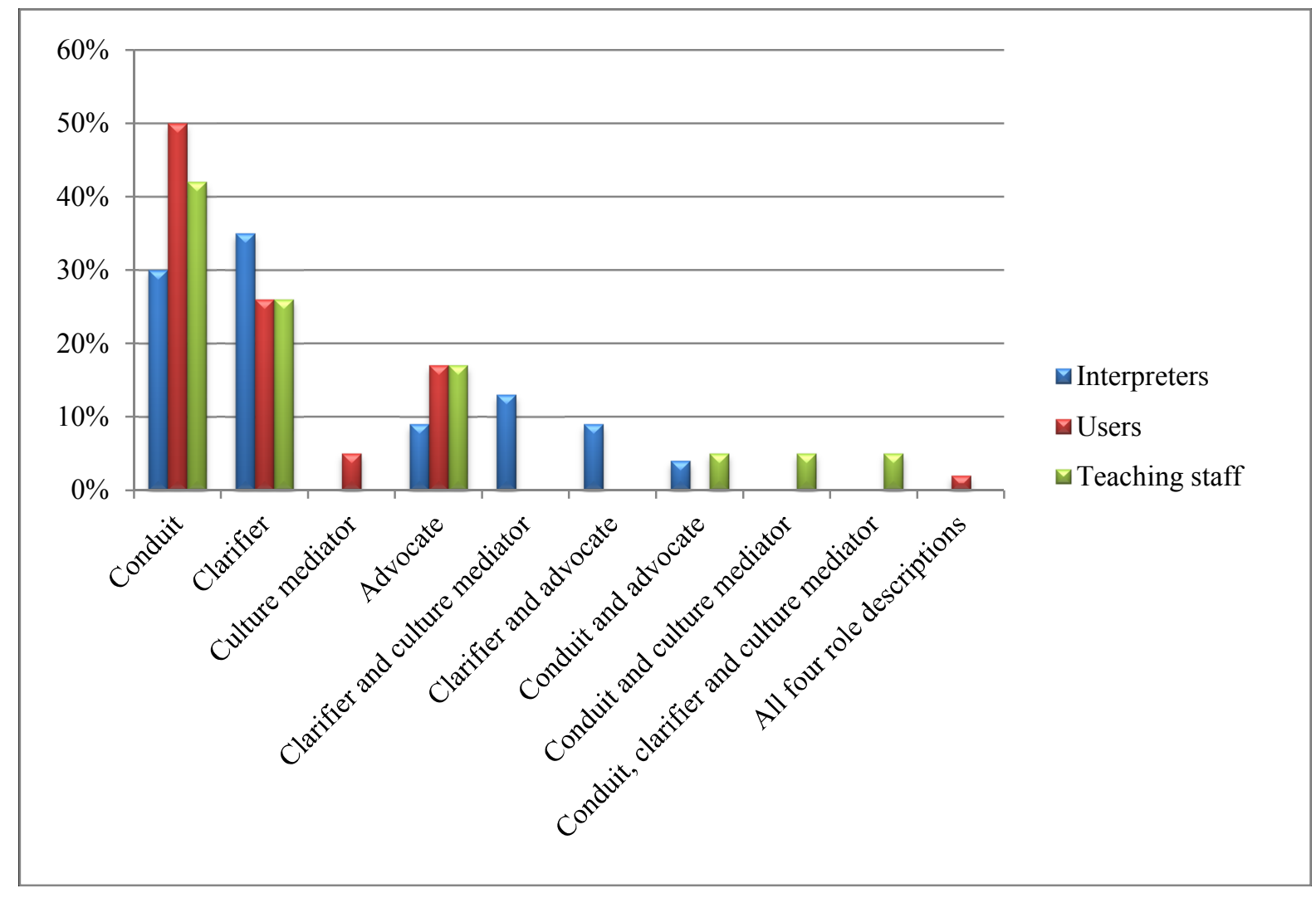

Figure 6. Combined quantitative data

The quantitative data confirms that the role of the educational interpreter is indeed a dynamic one and that what is expected of the educational interpreter does not necessarily take place in reality. Based on this data, the respondents were then asked why they made the selections in 
Questions 1 and 2. These responses allowed for an in-depth qualitative look into the reality of educational interpreting and allowed for an investigation of what defines educational interpreting. This investigation offered insight into the actions taken by educational interpreters which do not exist within any existing role model for interpreters. This confirms that educational interpreting should be viewed as a type of interpreting in its own right, which justifies an adapted role model for educational interpreting.

These actions, which were identified as being unique to educational interpreting, are represented in Table 2:

Table 2. Unique actions taken by educational interpreters

\begin{tabular}{|c|c|c|}
\hline \multicolumn{3}{|c|}{ Unique actions (by interpreter) } \\
\hline Teaching situations & $\begin{array}{l}- \\
- \\
- \\
-\end{array}$ & $\begin{array}{l}\text { The interpreter stops the lecture to retrieve more } \\
\text { information from the teacher. } \\
\text { Definite interaction between the interpreter and the teacher } \\
\text { (eye contact, body language). } \\
\text { The interpreter becomes involved in the lecture. } \\
\text { If the interpreter is a specialist in the field, s/he takes part } \\
\text { in the lecture. }\end{array}$ \\
\hline $\begin{array}{l}\text { Comprehension } \\
\text { situations }\end{array}$ & $\begin{array}{l}\text { - } \\
\text { student } \\
\text { book, }\end{array}$ & $\begin{array}{l}\text { The interpreter offers added information/content to } \\
\text { s outside of the lecture. } \\
\text { The interpreter ensures that the interpreting product } \\
\text { correlates with the teacher's message (in terms of text } \\
\text { transparencies and study guide). }\end{array}$ \\
\hline \multicolumn{3}{|c|}{ Unique actions (by teaching staff) } \\
\hline Teaching situation & - & The teacher provides the interpreter with correct terms. \\
\hline \multicolumn{3}{|c|}{ Other unique actions (by all roleplayers) } \\
\hline Teaching situation & - & $\begin{array}{l}\text { Interaction between interpreters, teaching staff and users } \\
\text { (eye contact, body language, offering signs). }\end{array}$ \\
\hline
\end{tabular}

Having determined these actions, it became evident that more data were needed to confirm these findings. A second questionnaire was developed in order to confirm whether the findings in Table 2 were in fact true of educational interpreting. This questionnaire was distributed among educational interpreters in order to validate these findings and to determine whether they should form the basis for a new role model specifically for educational interpreting.

The findings from the second questionnaire are represented in Figure 7: 

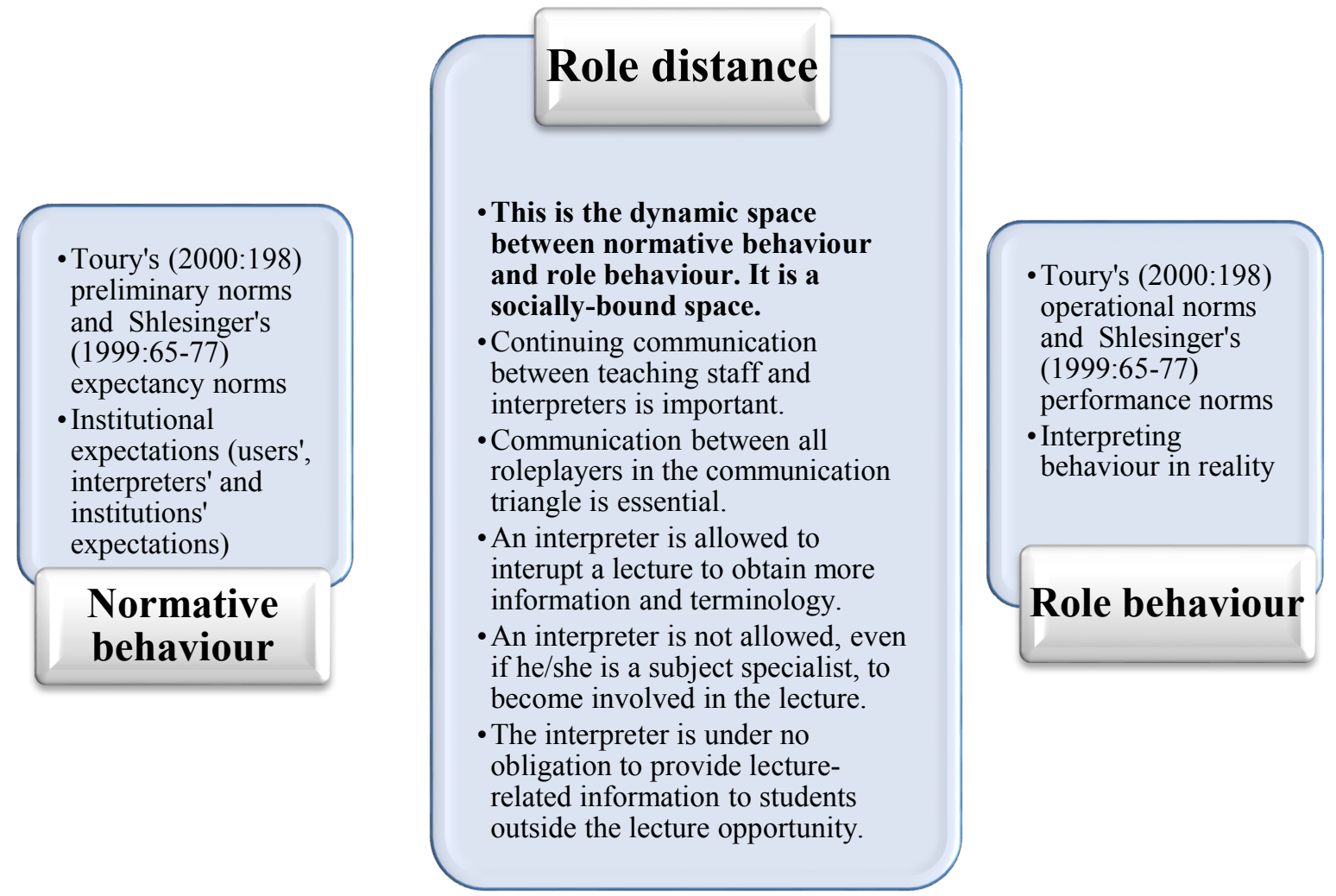

Figure 7. A model for the role fulfilment of educational interpreters

This study makes a contribution to existing role models by offering the possibility that the educational interpreter's role is changeable in nature, and moves on a continuum of involvement. Figure 7 represents the actions that are unique to educational interpreting and have been listed in terms of acceptability (according to the responses from educational interpreters). The model offers a clear role description for educational interpreting and is a practical model for the challenges faced by educational interpreters.

\section{Conclusion}

Within the social environment of educational interpreting, it cannot be expected of the educational interpreter to act as an uninvolved machine. The social nature of interpreting (and especially educational interpreting) not only requires but necessitates a more dynamic role model, which has been proposed in this paper.

This study proves that the educational interpreter indeed fulfils a changeable role, one which moves towards a more social-dynamic role model for interpreting. The proposed dynamic model gives clear and practical guidelines as to what is expected and acceptable within educational interpreting. It must be noted that this model does not stand in isolation, and that it remains the responsibility of interpreters, teaching staff and users to accept it in a macro context and internalise it in a micro context before it will reach optimal use and application. 


\section{References}

Anderson, R.B.W. 1978. Interpreter roles and interpretation situations: Cross-cutting typologies. In D. Gerver and H.W. Sinaiko (eds.) Language interpretation and communication. New York: Plenum Press. pp. 217-230.

Anderson, R.B.W. 2002. Perspectives on the role of interpreter. In F. Pöchhacker and M. Shlesinger (eds.) The interpreting studies reader. London: Routledge. pp. 208-217.

Angelelli, C.V. 2000a. Interpreting as a communicative event: A look through Hymes' lenses. Meta 45(4): 580-592.

Angelelli, C.V. 2000b. Interpreting pedagogy: A bridge long overdue. ATA chronicle (Translation Journal of the American Association of Translators) 29(11): 40-47.

Angelelli, C.V. 2003. The interpersonal role of the interpreter in cross-cultural communication: A survey of conference, court and medical interpreters in the US, Canada, and Mexico. In B. Louise, G.L. Bastin, I. Hemlin and H. Clarke (eds.) The critical link 3: Interpreters in the community. pp. 15-26.

Angelelli, C.V. 2004a. Revisiting the interpreter's role. Amsterdam: John Benjamins.

Angelelli, C.V. 2004b. Medical interpreting and cross-cultural communication. Cambridge University Press.

Angelelli, C.V. 2006. Validating professional standards and codes: Challenges and opportunities. Interpreting 8(2): 75-93.

Baker, M. 2005. Narratives in and of translation. SKASE Journal of Translation and Interpretation 1(1): 4-13. Available online: http://www.skase.sk/Volumes/JTI01/doc pdf/01 (Accessed 20 August 2008).

Bedeker, L. and I. Feinauer. 2006. The translator as cultural mediator. Southern African Linguistics and Applied Language Studies 24(2): 133-141.

Bhabha, H.K. 1994. The location of culture. New York: Routledge.

Borgatti, S. n.d. Introduction to grounded theory. Available online: http://www.analytictech.com/mb870/introtogt.htm (Accessed 20 October 2007).

Bothma, R. and M. Verhoef. 2008. Assessing the role of the interpreter in facilitating classroom communication. In M. Verhoef and T. Du Plessis (eds.) Multilingualism and educational interpreting: Innovation and delivery. Pretoria: Van Schaik. pp. 135-159.

Cresswell, J.W. 2009. Research design: Qualitative, quantitative and mixed methods approach. Thousand Oaks, CA: Sage Publications. 
Davis, J. 1994. Social creativity. In C.M. Hann (ed.) When history accelerates: Essays on rapid social change, complexity and creativity. Atlantic Highlands, NJ: Athlone Press. pp. 95-110.

Fozooni, B. 2006. All translators are bastards! South African Journal of Psychology 36(2): 281298.

Gentile, A., O. Uldis and M. Vasilakakos. 1996. Liaison interpreting: A handbook. Melbourne: Melbourne University Press.

Gercek, S.E. 2008. "Cultural mediator" or "Scrupulous translator"? Revisiting role, context and culture in consecutive conference interpreting. In P. Boulogne (ed.) Translation and its others. Selected papers of the CETRA research seminar in translation studies 2007. Available online: http://www.arts.kuleuven.be/cetra/papers/files/eraslan-gercek.pdf (Accessed 21 February 2014).

Gile, D. 1994. Opening up in interpretation studies. In M. Snell-Hornby, F. Pöchhacker and K. Kaindl (eds.) Translation studies: An interdiscipline. Amsterdam/Philadelphia: John Benjamins. pp. 149-158.

Gile, D. 2003. Justifying the deverbalization approach in the interpreting and translation classroom. Forum 1(2): 47-63.

Glaser, B.G. and A.L. Strauss. 1967. The discovery of grounded theory: Strategies for qualitative research. New Brunswick and London: Aldine Transaction.

Goffman, E. 1959. The presentation of self in everyday life. New York: Doubleday Anchor Books.

Goffman, E. 1961. Encounters: Two studies in the sociology of interaction. New York: BobbsMerrill.

Hale, S. 2004. The interpreter's identity crisis. Paper presented at the first conference of the International Association for Translation and Intercultural Studies: Translation and the Construction of Identity, 11-14 August 2004, Seoul, South Korea.

Kotze, A. and M. Verhoef. 2001. Die teksversorger as spookskrywer: Die teorie en professie onder die loep. Literator 22(2): 77-90.

Linell, P. 1997. Interpreting as communication. In Y. Gambier, D. Gile and C. Taylor (eds.) Conference interpreting: Current trends in research. Philadelphia: John Benjamins. pp. 49-69.

Marzocchi, C. 2005. On norms and ethics in the discourse on interpreting. The Interpreters' Newsletter 13: 87-107.

Merlini, R. and R. Favaron. 2003. Community interpreting: Re-conciliation through power management. The Interpreters' Newsletter 12: 205-229.

Mullamaa, K. 2006. Towards a dynamic role conception of liaison interpreters: An ethnographic study of self-descriptions of practising liaison interpreters in Estonia. $\mathrm{PhD}$ thesis. Estonia: Tartu University Press. 
Mullamaa, K. 2009. Towards a dynamic role model of liaison interpreters: Self-descriptions of practitioners in Estonia. New Voices in Translation Studies 5: 46-62.

Niska, H. 2002. Community interpreter training: Past, present, future. In G. Garzone and M. Viezzi (eds.) Interpreting in the $21^{\text {st }}$ century: Challenges and opportunities. Selected papers from the $1^{\text {st }}$ Forli Conference on Interpreting Studies, 9-11 November 2000. Philadelphia: John Benjamins. pp. 133-144.

Olivier, H. 2008. Process, product and performance: Exploring the differences between conference interpreters and educational interpreters. In M. Verhoef and T. Du Plessis (eds.) Multilingualism and educational interpreting: Innovation and delivery. Pretoria: Van Schaik. pp. 99-113.

Partridge, M. 2008. Influences on the interpreter's performance in the classroom. In M. Verhoef and T. Du Plessis (eds.) Multilingualism and educational interpreting: Innovation and delivery. Pretoria: Van Schaik. pp. 67-81.

Pöchhacker, F. 2001. Quality assessment in conference and community interpreting. Meta 46(2): 410-425.

Pöchhacker, F. 2007. Introducing interpreting studies. New York: Routledge.

Poyatos, F. 1997. The reality of multichannel verbal-nonverbal communication in simultaneous and consecutive interpretation. In F. Poyatos (ed.) Nonverbal communication and translation: New perspectives and challenges in literature, interpretation and the media. Philadelphia: John Benjamins. pp. 249-282.

Pym, A. 1997. Method in translation history. Manchester: St. Jerome Publishing.

Pym, A. 2010. The translator as non-author, and I am sorry about that. Available online: http://usuaris.tinet.cat/apym/on-line/translation/2010 translatore_as_author.pdf (Accessed 21 March 2011).

Reeves, N.B.R. 1994. Translating and interpreting as cultural intermediation: Some theoretical issues reconsidered. In R.K. Seymour and C.C. Liu (eds.) Literary studies East and West. Translation and interpreting: Bridging East and West, selected conference papers. Honolulu: University of Hawaii Press. pp. 37-50.

Rudvin, M. 2006. Issues of culture and language in the training of language mediators for public services in Bologna: Matching market needs in training. In D. Londei, D.R. Miller and P. Puccini (eds.) Insegnare le lingue/culture oggi: Ilcontributodell' interdisciplinarita. Bologna: CeSLiC. pp. 57-72.

Schjoldager, A. 1994. Interpreting research and the "manipulation school" of translation studies. Hermes, Journal of Linguistics 12: 65-89. 
Shlesinger, M. 1999. Norms, strategies and constraints: How well do we tell them apart? In A.A. Lugris and A.F. Ocampo (eds.) Anovar/Anosar: Estudios de Traducción e Interpretación. Vigo: Universidade de Vigo. pp. 65-77.

Snell-Hornby, M. (ed.) 2006. The turns of translation studies: New paradigms or shifting viewpoint. Philadelphia: John Benjamins.

Strauss, A.L. and J. Corbin. 1990. Basics of qualitative research: Grounded theory procedures and techniques. Newbury Park: Sage Publications.

Strauss, A.L. and J. Corbin. 1994. Grounded theory methodology: An overview. In N.K. Denzin and Y.S. Lincoln (eds.) Handbook of qualitative research. Thousand Oaks, CA: Sage Publications. pp. 273-285.

Strauss, A.L. and J. Corbin. 1997. Grounded theory in practice. Thousand Oaks, CA: Sage Publications.

Strauss, A.L. and J. Corbin. 1998. Basics of qualitative research: Techniques and procedures for developing grounded theory. Thousand Oaks, CA: Sage Publications.

Swabey, L. 2007. Healthcare interpreting: Research and resources. Available online: www.asl.neu.edu/ nciec/resource/docs/MedicalInterpertingSwabey.pdf (Accessed 10 August 2008).

Tate, G. and H.G. Turner. 2002. The code and the culture: Sign language interpreting - In search of the new breed's ethics. In F. Pöchhacker and M. Shlesinger (eds.) The interpreting studies reader. New York: Routledge. pp. 373-383.

Toury, G. 1995. Descriptive translation studies and beyond. Philadelphia: John Benjamins.

Toury, G. 1999. A handful of paragraphs on 'translation' and 'norms'. In C. Schäffner (ed.) Translation and norms. Clevedon: Multilingual Matters. pp. 9-31.

Toury, G. 2000. The nature and role of norms in translation. In L. Venuti (ed.) The translation studies reader. London: Routledge. pp. 198-211.

Van den Broeck, R. and A. Lefevere. 1979. Uitnodiging tot de vertaalwetenschap. Muiderberg: Countinho.

Verhoef, M. and J. Blaauw. 2009. Towards comprehending spoken-language educational interpreting as rendered at a South African university. In J. Inggs and L. Meintjies (eds.) Translation studies in Africa. Continuum Studies in Translation. New York: Continuum International Publication Group. pp. 204-222.

Verhoef, M., W.A.M. Carstens and K. Van de Poel. 2003. Op weg na 'n koherente siening van die taal- en tekspraktyk. Literator 24(3): 15-29.

Wadensjö, C. 1998. Interpreting as interaction. London: Longman. 